\title{
Representations of Policing Problems and Body-Worn Cameras in Existing Research
}

In this article, we analyse scholarly publications on body-worn cameras (BWCs) to shed light on scholars' grounding assumptions about BWC technology and the policing problems assumed to be amended by it. We conducted a systematic search and a double-blind review, including 90 peer-reviewed journal articles, and analysed how scholars warrant their studies, their findings and their recommendations. We found that BWC research largely investigates the effectiveness of BWCs worn by police officers in the U.S. and build upon a set of dominant policing problem representations: the police crisis in the U.S. and the police use of force, lack of oversight and control of police officers, citizen dissatisfaction and lack of police legitimacy, and police officer resistance towards BWC use. Assumptions underlying all four problem representations is that BWC technology will amend these problems and is legitimate and useful if the public supports it. Taken together, this enhances the representation of BWC technology as a self-evident means of improving community relations and police legitimacy in the U.S. Finally, we provide recommendations for future research on BWCs, particularly the need for research departing from altogether different problem representations.

Keywords: body-worn camera, body-worn video, problem representations, policing, social control professionals

\section{Introduction}

Body-worn cameras (BWCs) are a technology that allows users to record video and sound of events around them without the need for hand-held cameras. In this article, we 
depart from the notion of BWCs as a solution to one or more policing problems and, as such, a criminal justice and crime control phenomenon worthy of study. We analyse all available research articles about BWC use in social control professions published in English in academic journals until May 2020. This we do to shed light on scholars' grounding assumptions about both the state of contemporary policing problems and the utility of BWCs in connection to these. Instead of taking BWC technology for granted as a self-evident response to crime, misbehaviour and other policing problems, we ask what BWCs are portrayed to be a response to, how links between the use of BWC technology and policing problems (be they crimes, misbehaviour or other types of problems) are expressed or assumed in the existing BWC research.

As will be shown, BWC technology is assumed to have several positive effects. For example, it is assumed to deter both police officers and citizens from unwanted and unlawful behaviour, and thereby produce a 'civilizing effect', in turn leading to reductions in police use of force as well as citizen resistance, violence and complaints. It is also recurrently assumed to help improve police-community relations. A majority of the BWC research focuses on measurable effects of BWCs, and systematic metareviews of the effects of BWCs have been published (see e.g. Gaub \& White, 2020; Lum et al. 2020). While we have applied some of the procedures typical of systematic reviews, our main aim is not to produce conclusions about whether BWC technology 'works' or not; nor is it to establish the actual effects of BWCs based on the existing empirical research. Instead, we aim to shed light on scholars' grounding assumptions about both contemporary policing problems and BWC use and utility, to render visible assumptions and taken-for-granted truths. In sum, we investigate what policing problems BWCs are depicted to be solutions to, and how these problems as well as links between the solution (BWCs) and problems are represented in scholarly work. 
Our approach draws on Kraska (2006) and Duffee (2015), who discuss the importance of criminal justice and crime control phenomena - in our case BWC use as reported in scholarly work - as study objects in their own right (inquiring into why they are suggested and put into practice in the first place), rather than as self-evident outcomes or straightforward responses to crime and social deviance. We furthermore draw on Bacchi $(2009 ; 2012)$, whose approach to policy analysis encouraged us to think about what problems the current deployment of BWCs and development of BWC policies are supposed to solve as represented in published research work.

The study of criminal justice and crime control phenomena has often been depicted as studies of 'responses' to crime. Arguably, at any point in time there are always different possible ways of dealing with (policing) problems, depending on how problems are defined and represented (Loseke, 2003). The study of criminal justice and crime control phenomena has furthermore often 'been assigned the limited role of developing the most effective and efficient crime control practices through applied, policy, and evaluation research' (Kraska, 2006, p. 170; see also Duffee, 2015), based on the assumption that studying crime control and criminal justice issues is a practical (rather than theoretical) endeavour "concerned only with the "what works" and "how to" of crime control' (Kraska, 2006, p. 170). In contrast to the majority of the available BWC research aiming to establish 'what works' in terms of BWCs, we take an interest in societal processes perceived as policing problems as expressed in scholarly BWC research, which in turn have led scholars to argue for (or against) the implementation and use of BWCs as a form of criminal justice control. We ask why BWC technology has become a crime control and criminal justice measure, studied and suggested as a tool to combat policing problems, as implicated in BWC research and how it is assumed to work, convinced that studying the why of a crime control and criminal justice 
measure such as BWCs is just as important as studying the why of crime and deviance (Becker, 1963; Christie, 2001; Duffee, 2015; Garland, 2001; Kraska, 2006; Simon \& Feeley, 1994). Understanding why BWCs have been implemented and used, and why scholars (by drawing on empirical research) argue for the use of BWCs, based on certain assumptions about both policing problems and the effects of BWCs, is crucial for the development of successful reforms to address policing problems (cf. Kraska, 2006, p. 171). Studying the trend of BWC use and BWC research - and making theoretical sense of this trend - gives us clues as to how policing practices should and should not be evaluated, and policing problems addressed, in the contexts where they are taking place.

The article proceeds as follows. We begin by outlining our analytical approach to the study of BWC use as a crime control and criminal justice phenomenon as reported in available BWC research. After accounting for our methodological procedures for sampling and selecting BWC research to include in our study, we then discuss key policing problems supposed to change by BWC use as represented in BWC research. In conclusion, we discuss what - taken together - remains unsaid or unproblematized as well as (possible) implications of the policing problem representations dominating BWC research.

\section{Our Analytical Approach}

We regard a contextual understanding of $\mathrm{BWC}$ research to be important. BWC use and research was initiated on a large scale in the U.S. in the 2010s following a number of lethal shootings by (white) police officers of (African American) men. Immediately following these deaths, in 2014-2015, U.S. President Obama established a Task Force on 21 st Century Policing involving practitioners, policymakers and researchers working to address the distrust between communities and the police, and 'criminal justice 
advocates called for greater measures to hold police officers accountable for their actions' (Simmons, 2014, p. 882). In this context, BWCs were seen as a 'tool in the efforts to increase accountability and transparency within law enforcement agencies' (Simmons, 2014, p. 890; see also Naoroz \& Cleary, 2019). In the period 2014-2020, the BWC research field has grown dramatically (White 2014, Lum 2020). When analysing the existing BWC research it became clear that BWC use is represented as a possible solution to racialized police-community relations as well as a host of other types of problems, as will be shown.

Arguably, the introduction and use of BWCs represent a considerable shift in the criminal justice and control apparatus. As with examining any other new criminal justice and social control measure or initiative, examining why BWCs are introduced, researched and suggested, including the policing problems assumed to be amended by their use, yields important insights into possible 'irrationalities, missteps, and disconcerting implications' (Kraska, 2006, p. 180). The societal processes 'that lead to criminal justice controls' are important social research topics (Duffee, 2015, p. 6). Following Duffee (2015, p. 10f.), we do not assume that a 'rational model' underlies the implementation of BWCs as a criminal justice initiative. The process of criminal justice policymaking - and research - is arguably to some extent politically driven, and it is simply not the case that measures are implemented in practice based on 'what works' (Duffee, 2015, p. 10f.).

As mentioned, BWCs are believed to have a 'civilizing' and deterrence effect on officers in the sense that they use less invasive strategies, leading to improved relations between the police and the public, the prevention of tragic incidents, and fewer complaints by citizens (e.g. Jennings et al., 2015). However, the research results regarding the extent to which BWCs can curb unacceptable police behaviour are mixed, 
and there is no consensus in the research community on how to interpret existing results (Gaub \& White, 2020; e.g. Lum et al., 2019; Malm, 2019). In several studies, mixed or negative research findings on the effects of BWCs tend to be explained away by reference to 'implementation failures', and scholars call for further research on police activation of BWCs or even recommend policymakers not be 'disheartened' by the mixed research evidence and police agencies to 'consider a BWC program' (Malm, 2019, p. 121f.; see also Drover \& Ariel, 2015; Ariel et al., 2016a; Hedberg et al., 2017; Sousa et al., 2018; Lawrence et al., 2019). Such arguments are examples of a kind of 'modifying work' (Asdal, 2015) where research articles take part in creating a reality in which the assumption that BWC technology will solve policing problems is fortified. In that sense, published research articles have a transformative capacity (Asdal, 2015), as they can modify and transform our understanding of policing problems and solutions, which makes it all the more important to analyse assumptions underlying research studies made and published. We regard research publications (this one included) not as objective or neutral reports. They are produced for the purpose of communicating truth claims, and when disseminated and consumed they thus contribute to transforming attitudes towards criminal justice effects of BWCs and policing.

By our analysis of problem representations, the politics involved in policymaking and research is made visible (Bacchi 2012). Every piece of published research is in a sense a 'prescriptive text' expressly or implicitly resting on one or more problem representations, indicating that a change of some (often specific) type is needed. It is possible to 'deduce' or work 'backwards' to understand underlying assumptions about what is wrong and what needs to be done about it (Bacchi 2012, p. 4). We regard published research as our empirical materials and from the texts we 'deduce' assumptions about what is wrong in policing and what needs to be done. By 
designing research studies building on explicit or implicit problem representations what is wrong in policing - and by presenting arguments on why BWCs are to be introduced as a solution, published research contributes in a powerful way to produce what is 'real' about both policing problems and BWCs. Therefore, it is important to subject also published research to scrutiny and point towards possible adverse effects that are thereby 'set in operation' (Bacchi 2012, p. 7). Like all researchers, those in the field of BWC research are active in constructing or producing problems and solutions. We are interested in finding out when BWC use is proposed and how policing issues are thought about, including what needs to be changed and how. In our analysis, we therefore focus on the 'background "knowledge" that is taken-for-granted', and both 'elicit the assumptions and beliefs' held as true or self-evident in research and the presuppositions of the problem representations (Bacchi 2009, p. 5). Arguably, then, published research work comprises socially produced texts and as such they are sources of information about the society that has produced them (Becker, 2007), in our case, information about dominant views of the specific problems involved in policing, what needs to change and how (or if) BWC use could help in this regard. In mapping dominant views of BWC in published research on the topic, individual contributions or potential motives of individual researchers thus become less important, and in our article, quotes from published research work function as illustrative examples of existing problem representations.

Our analysis of altogether 90 research publications focused on how policing problems are represented in the BWC research and how BWCs are assumed to help address them. We followed Bacchi's (2009, p. 48) analytical approach, which when translated to our research review, resulting in the following analytical questions. 
(1) What are the problems for which BWCs are depicted to serve as solutions? How are these problems represented in scholarly work?

(2) What are the presuppositions or assumptions that underlie the studies?

(3) What remains unproblematic in the dominant problem representations?

(4) What possible consequences do dominant problem representations produce?

The first, second and third questions are analysed and illustrated in depth in the empirical parts of this paper. The fourth question, concerned with implications of dominant problem representations, is discussed in the concluding section. Although the problems that BWCs are assumed to solve are sometimes explicitly expressed in the published scholarly work, at other times, analyses of implicit problem representations underlying the research are needed to fully grasp authors' arguments. As part of our analysis of BWC publications, we coded all publications specifically focusing on author arguments about their study object and the importance of their study (the 'so what' of the study; why the research is important and useful), the ways that the research questions, aims and hypothesis (if included) were formulated, how results were presented, and how findings from analysis of BWC use and utility were generalized. Not all problem representations are explicitly stated, but are implicit in the line of argument in the sense that arguments only make sense if based on certain assumptions or preconditions. Implicit problem representations were coded in larger text chunks combined with memos on interpretations of the problem representation. Based on our analysis of the publications, we deduced assumptions about policing problems and the effects of BWCs, and subjected these to critical scrutiny (see Bacchi, 2012). We identify the host of policing problems expected to be solved by BWC use, including assumptions underlying the research studies, discuss implications of dominant problem representations, and finally ask whether there are altogether different measures that 
need be taken to bring about the desired change in policing and community-police relations.

\section{Research Review Procedures}

To understand the 'nature of research activity' (Arksey \& O'Malley, 2005, p. 21) in the field of BWC research, and 'how research is conducted' (Munn et al., 2018, p. 2) in it, and to systematically produce the published scholarly work that we regard as our empirical materials and analyse them, we conducted a scoping review. This approach to sampling and selecting scholarly work furthermore ensures necessary breadth and provides transparency in terms of our procedures (Arksey \& O’Malley, 2005; Levac et al., 2010). Our scoping review of peer-reviewed, empirical BWC research includes 90 peer-reviewed sources. We limited our review to peer-reviewed publications only, as we regard this as a sign that the paper has been approved by the wider scholarly community, and disseminated and read by an audience of scholars and perhaps to some extent practitioners.

We followed the process for scoping reviews as originally laid out by Arksey and O'Malley (2005), and later refined by Levac et al. (2010) and Colquhoun et al. (2014). To begin with, we searched the field and listed a number of high-impact publications on BWCs and potential keywords. Following Arksey and O'Malley's (2005) recommendation, we then collaborated with two librarians specializing in systematic reviews at the Gothenburg University Library (see also Gough et al., 2017). The librarians used our lists of high-impact publications and potential keywords to identify the keywords and databases that provided the most comprehensive search results of articles on BWC, while at the same time keeping redundant results to a minimum. Criminal Justice Database, IBSS and PsycInfo were identified as providing 
the most accurate results. In addition to these databases, we manually searched reference lists of the articles included in the review, thereby locating some articles published in journals not revealed by our databases. We then manually searched these journals. In total, we found 16 additional articles through manual searches. Figure 1 provides a detailed description of the selection process. We began our scoping review in June 2019 and did the last search for articles to update the review in June 2020, including articles published until May 2020 (cf. Gough et al., 2017). Our inclusion criteria were that articles should be in scientific and peer-reviewed journals, for reasons stated above, written in English, as articles in English are most common and disseminated, and lastly, should concern social control professions (broadly defined as occupations engaged in order-management tasks). Policing today is marked by pluralism, i.e., a multiplicity of actors and agencies, public as well as private, are involved in policing (Boels \& Verhage, 2016; Jones \& Newburn, 2006). One of the leading producers of BWCs use pictures of private security officers when they advertise their BWCs. ${ }^{i}$ Hence, we had no reason to believe that their use and thereby research on BWCs would be limited to police authorities and officers. This turned out to be the case (with one exception).

We conducted a double-blind screening of titles and abstracts of 289 studies included in our review. Each of us read all abstract separately and rated them in terms of 'include' of 'exclude' based on the following exclusion criteria: wrong population (users outside the social control sector), not an empirical study (e.g. a theoretical contribution, essay, debate, literature review), and not about BWCs, i.e., body-worn cameras (e.g. research on the Biological Weapons Convention [hence, the same abbreviation BWC] or studies using BWCs to collect empirical data, but not examining their impact). We had a high degree of interrater reliability in that our ratings were 
consistent for the vast majority of the articles ( $>95 \%)$. After an initial screening based on the abstracts, we then applied the same exclusion criteria to the 96 articles that remained for full-text screening. Eventually, we chose to include 74 articles in our final review together with the 16 found through manual searches of reference lists and specific journals not included in the databases. Our systematic review thus included 90 empirical and peer-reviewed publications (marked with * in the list of references) in total.

\section{[Insert Figure 1 about here]}

Of the 90 articles on BWCs included in our analysis, 69 were conducted in the academic disciplines of criminology and criminal justice, and 76 were conducted in the U.S. ${ }^{\text {ii }}$ In 42 of the 90 articles, the authors explicitly discussed the fatal shootings of black men by white police officers. Furthermore, 68 studies use quantitative methods. Although we were looking for BWC research studying all sorts of social control professions, we found that only one study concerned staff other than police officers (Ariel et al., 2019, studying gate line officers at railway stations in the UK.).

\section{Policing Problem Representations}

In the following, we discuss key policing problems supposed to change by BWC use as represented in BWC research: the police crisis in the U.S. and police use of force, the lack of oversight and control of police officers in operational duties, the lack of police legitimacy and citizen dissatisfaction, and - finally - police officer resistance towards use of BWCs.

\subsection{Problem Representation: The Police Crisis in the U.S. and Police Use of Force}

The majority of the research on BWCs investigated the effectiveness of cameras worn by police officers in the U.S. (76 of the 90 articles), some research including 
comparisons with several other countries (Ariel et al., 2016a, 2016b, 2017), and 68 out of 90 articles were based on quantitative methods using police officers as research participants. In studies of BWC effects, researchers generally started out by recognizing positive expectations about the effectiveness of BWCs regarding the racialized police crisis in the U.S. In some research publications, positive expectations are generally held to be true and valid:

Recent police use of force incidents have highlighted the need for expanded police implementation of body-worn cameras (BWC). Access to BWC data may have mitigated conflicts between the police and the public, obviated ensuing riots and violence, and abrogated the deterioration of police and community relations. The shooting of Michael Brown by a Ferguson police officer, had it been captured on a BWC, could have cleared, or implicated, that officer of the allegations of excessive force raised in the death of an unarmed suspect. (Pelfrey \& Keener 2016: 491)

In other research publications, the expressly stated expectations of others, e.g. the news media, politicians and police leaders, are commented on, while the lack of research support for such claims is emphasized (e.g. Ariel et al., 2016b; Boivin et al., 2017; Braga et al., 2018; Schneider, 2018). Consider this example: In recent years the use of police body-worn-cameras by police has received extensive media attention. These devices are commonly believed to achieve several aims, including: reducing police use-of-force and complaints against officers, enhancing police legitimacy and transparency, increasing prosecution rates and improving evidence capture by the police. The publicity has been so great that many go on to assume that cameras can fundamentally change 'flawed' police practices. [...] Despite great promises, there is no research evidence on the benefits of body-worn-cameras. (Ariel et al., 2015, p. 510)

Arguably, both empirical research activities and published articles bear the marks of the societal and political context, as well as available funding opportunities and 
stakeholders' problem definitions. The field of BWC research is no exception, particularly given former President Obama's Task Force on 21st Century Policing.

Soon after the police shooting in Ferguson, Missouri, in 2014, when a white police officer fatally shot 18-year-old African American Michael Brown, the protests that followed and police responses to protests, and the massive media and political debates, BWCs were introduced in police agencies across the U.S. (Culhane \& Schweitzer, 2018), and President Obama's Task Force on 21st Century Policing was established. The latter announced that the Obama administration 'would spend \$75 million' on BWC implementation and increase funding for research (Lawshe et al., 2019, p. 80). Hence, both BWC implementation and research on police use of BWCs increased dramatically, and have been conducted in the context of a crisis in police work in the U.S. The police crisis in the U.S. has had such an impact on the research field of BWCs that even researchers from China and Turkey have argued for their studies by comparing citizens' mistrust and national police behaviour with the events in the U.S. (Demir et al., 2020; Jiang et al., 2020).

Due to the fact that most BWC research has been carried out in the context of the police crisis in the U.S., many studies focus specifically on the effects of BWCs on police use of force. Taken together, the existing research findings on the effects of BWC on police use of force are inconclusive, as demonstrated by Lum et al. (2020) and Gaube and White (2020). On the one hand, BWC use has been shown to reduce police use of force (Ariel et al., 2015; Henstock \& Ariel, 2017; Jennings et al., 2015, 2017). On the other hand, others, such as Ariel and colleagues, have shown that BWCs do not reduce the use of police force, and that 'cameras increased the likelihood of an officer being assaulted during a shift compared to not wearing the cameras' (Ariel et al., 2016a, 2016b, p. 750; see also Koslicki, 2019). The inconclusiveness it not a result of a lack of 
research. In Lum et al.'s (2020) systematic review of 30 studies, 26 of them studied BWCs' impact on officers use of force.

A premise of most U.S.-based research is that decreasing police use of force is (always) a good thing. However, police use of force can be both justified and unjustified. When Ariel (2016a) found that police use of force increased by $15 \%$ among officers wearing a BWC, the author interpreted it as evidence of justified use of violence. In a later study, Ariel et al. (2018) found that while BWCs generally reduced both police use of force and officers' exposure to violence, they may also increase their exposure to violence if officers are passive, i.e., do not dare to use violence for fear of reprimand. Such passivity was argued to pose a direct danger because not intervening when necessary escalated violence. Hence, a reduction in use of force in such cases is negative for police officers. The effect of 'de-policing' is, however, also contested. Wallace and colleagues (2018) did not find support for their hypothesis that 'depolicing', i.e., a 'camera-induced passivity', might be an unintended consequence of police BWCs.

The meaning of 'use of force' is sometimes not defined at all (e.g. Braga et al., 2019; e.g. Headley et al., 2017; Sutherland et al., 2017). In other research publications, 'use of force' is defined very broadly, such as, e.g., 'any physical restraint on the force continuum $[\ldots]$ beyond the use of verbal commands' (Ariel et al., 2016b, p. 750), or anything 'from striking a subject with a body appendage (e.g., hand, fist, foot, or other body appendage) up to and including lethal force' (Groff et al., 2019, p. 5). There are also examples of publications reporting more precise definitions based on, e.g., making a distinction between 'basic control' and 'use of force' where the latter refers to interventions with the use of some sort of equipment - 'the use of (a) OC spray, (b) baton (c) Taser, (d) canine bite or (e) firearm' (Ariel et al., 2015, p. 521). The variety of 
definitions of use of force, as well as the wide variety of actions that can be included in the variable 'use of force' in a single study, make it difficult to evaluate interpretations of whether or not an increase or decrease in use of force represents justifiable or unjustifiable use of force. What is lacking in both problem representations and methodological operationalization is a discussion of matters such as when and why an instance of use of force is a case of misconduct and therefore should be avoided.

The focus on police use of force in the problem representations in published research must be understood in relation to the police crisis in the U.S. Ultimately, the problem representation of police use of force is the result of underlying problems of police-community relations and structural racism. A question that needs to be asked more often in research on BWCs and police use of force is whether or not BWCs can address these underlying problems, or if implementation and use of BWCs - and problem representations of use of force - may even obscure underlying problems and hinder other measures.

\subsection{Problem Representation: Lack of Oversight and Control of Police}

\section{Officers}

Although a strong focus has been on police use of force, the debate around the police crisis in the U.S. has also had broader focus on police behaviour that is visible in the research on BWC and its problem representation. Researchers have, for example, examined the effects of BWCs on police officers' behaviour and activities (e.g. Fallik et al., 2018; Heumann et al., 2018; Rowe et al., 2018) in terms of neutrality, respectfulness and caring (McCluskey et al., 2019), and how they used BWC technology (e.g. Guzik et al., 2019; Koen et al., 2019; Owens \& Finn, 2018; Rowe et al., 2018; Young \& Ready, 2018). The main assumption in the research is that being monitored and controlled by the BWC will alter officers' behaviours, their ways of managing the citizens they serve, 
and improve police-citizen interactions more generally. For example, Jennings and colleagues (2015) found that BWCs improved the way police officers dealt with resistance, and reduced external complaints by $65.4 \%$. They recommended that police organizations introduce BWCs and claimed that they improve the relationship between the police and the public and prevent 'tragic incidents'. Quantitative studies have also shown police officers with BWCs to be less likely to stop and check citizens, less likely to make arrests, and more likely to interact with the public (Groff et al., 2019; Lawrence \& Peterson, 2019; Lawrence et al., 2019; Ready \& Young, 2015). Furthermore, one study found that with BWCs recording the details, officers felt more focused on interactions with citizens and suspects (Guzik et al., 2019), and another found that police officers felt their reports improved (Koen et al., 2019). However, in their metaanalysis of effects of BWCs, Lum and colleagues found no statistically significant effects on these sorts of officer behaviours (Lum et al., 2020).

Improved officer behaviour is measured in several different ways by, e.g., use of force, type of interventions, number of arrests, and citizen complaints. The use of complaints as measurements of police behaviour rests on the assumption that there is a correlation between officer misbehaviour and citizen complaints. Use of BWCs is assumed to change police officers' interventions, interactions with citizens, and particularly how they deal with resistance. This is in turn assumed to reduce complaints from those subject to intervention (which in turn is taken to signal satisfaction with the police). Many studies have reported that BWCs led to fewer citizen complaints about police conduct (Ariel, 2016a; Ariel et al., 2015, 2016a; Braga et al., 2018, 2019; Hedberg et al., 2017; Jennings et al., 2015; Koen et al., 2019; Mitchell et al., 2018; Owens \& Finn, 2018; Sutherland et al., 2017), the exception being Groff et al. (2019), who found that complaints did not decrease, and this effect was found statistically 
significant in Lum and colleagues' meta-review (Lum et al., 2020).

However, as observed by Lum et al. (2019, p. 100), using 'complaints as a measure of police behaviour or officer-citizen interaction' is problematic since complaints are 'rare events' that only 'reflect the tail end of the distribution of policecitizen interactions'. A decrease in complaints may be an effect of improved officer behaviour. It may, however, also be an effect of fewer unfounded complaints by citizens due to the video recordings, or of other so far unknown mechanisms. Arguably, there is a risk that scholars and wider audiences will rely on research results about reductions/increases in numbers of citizen complaints to draw inferences about police work and the character of police-citizen interactions in general.

Although BWCs may alter police behaviour, such alterations may have unintended and negative implications. Some qualitative studies have shown that officers expressed concerns and fears that BWCs restrict their actions because certain actions, although necessary, do not look good on video (Fallik et al., 2018; Heumann et al., 2018). Similarly, Rowe et al. (2018, p. 88) found that police officers felt BWCs made officers feel constrained, robotic and 'changed the nature of the interactions they have with the people they stop'. A more thorough discussion of what type of changed behaviour improves police practice, and what type does not, is a prerequisite if research on BWCs seeks to shed light on whether or not BWCs is an instrument that will help control police officers and provide better service in line with regulation and policy.

One solution to improve oversight and control of officers, proposed in published BWC research, is to make it mandatory to wear a BWC and to remove officers' discretion as to when and to what extent to record events as well as having supervisors systematically reviewing officers' recordings (e.g. Ariel et al., 2016a; Drover and Ariel, 2015; Lawrence et al., 2019, p. 251). Such a solution mimics more general political 
ideals of transparency, monitoring and (internal) controls as a solution, or substitute, to a lack of trust and legitimacy (Lyon, 2001; Power, 2000). A broader scholarly discussion on implications of more control and surveillance within the police - such as how it impacts the public's view of the police and the general ability for the profession to operate and apply necessary discretion (cf. Lipsky, 1980) - is much needed.

\subsection{Problem Representation: Citizen Dissatisfaction and Lack of Police Legitimacy}

Misbehaviour and unlawful use of force by police officers in the U.S. are constructed as a problem causing citizen dissatisfaction and the police to lose legitimacy in the eyes of the public. BWCs have been depicted as a technology that may help restore police legitimacy in the eyes of the public. Consider for example:

Police BWCs seem like the logical and inevitable next step in the use of electronic surveillance to improve the different components of the criminal justice system. /.../ There are also a variety of additional advantages to BWCs, including an increase in the transparency of police - citizen interactions (Gramagila \& Phillips, 2018, p. 314)

Such a problem representation is preeminent in studies on public attitudes towards police use of BWCs, in studies of the willingness to provide witness testimony, and in studies of how viewing BWC recordings impacts evaluations of officers' actions. A basic assumption in the latter is that with BWC recordings, evaluation of whether an officer's actions are justifiable can be improved:

BWCs, thus, increase the transparency of front-line policing (Ready and Young, 2015; Scheindlin, 2015). What can be recorded can be subsequently reviewed or scrutinized, and officers became more accountable as BWCs increase the need for oversight and reflection on their own actions (Lumina, 2006; Reiner, 1993; Walsh and Conway, 2011). (Mitchell et al., 2018, p. 511)

Most studies on the public's attitude towards police use of BWCs have been conducted 
in the U.S., and reported that the public is in the main very positive (Graham et al., 2019; Kerrison et al., 2018; Miethe et al., 2019; Sousa et al., 2018; White et al., 2017; White, Gaub, et al., 2018). Citizens are positive because they believe that BWCs will decrease police violence (Miethe et al., 2019), increase transparency and accountability (Graham et al., 2019), improve evidence, and reduce corruption, while improving citizens' behaviour and reducing the number of complaints (Demir, 2019; Sousa et al., 2018). Similarly, Todak and colleagues (2018) reported that 'non-police stakeholders' expect BWCs to improve evidence, increase public confidence in the police, and reduce the number of 'erroneous' complaints. Lee et al. (2019) showed that even citizens being arrested and detained were supportive of BWCs because they believed they would improve citizen and police behaviour. In terms of the effects on citizen behaviour, the willingness to provide witness testimony has been studied and the results indicate that BWCs have a positive impact (Hamm et al., 2019).

Regarding how BWC use impacts evaluations of officers' actions, McCamman and Culhane (2017) found that participants who watched a BWC video were significantly less prone to believe that the police violence was justified compared with those who read about the incident or heard an audio recording (see also Saulnier, Burke, et al., 2019). By contrast, two studies found that participants who watched a BWC recording perceived the incident as more justified/less intentional than those who watched a dashcam or surveillance camera recording (Jones et al., 2020; Turner et al., 2019). Culhane et al. (2016) found that societal events and debates influence how citizens interpret BWC recordings. Ramirez (2018) found that very few citizens watched recordings published by the police on the latter's YouTube channel. Citizens who watched BWC recordings of a police shooting, as part of a research experiment, were more likely to perceive the shooting as justified before the Ferguson shooting than 
those who watched the same recording after the shooting in Ferguson (Culhane et al., 2016). Studies have also shown that citizens with positive attitudes towards the police perceive the police to be more objective than those with critical attitudes towards the police (Jones et al., 2018), and people identifying with the police tend to interpret BWC recordings in a way that benefits the police (Jones et al., 2017).

Hence, placing BWCs on police officers may lead to either more positive or more negative citizen attitudes towards the police among citizens, depending on current events in society and their media coverage, and depending on citizen attitudes towards the police in general (Culhane \& Schweitzer, 2018; McCamman \& Culhane, 2017). Consequently, it seems likely that societal events and debates as well as citizens' degree of positive attitudes towards and identification with the police impact evaluations of the justifiability of police officers' actions much more than the availability and review of BWC recordings per se.

While research on citizen attitudes towards police use of BWCs is based on the often implicit but certainly correct precondition that the police ultimately need legitimacy in the eyes of the public to achieve its mission, research findings about public attitudes towards police BWCs say little about the efficiency of BWCs in achieving police legitimacy. For example, White and colleagues (2017, p. 699) reported that citizens were satisfied with the police, regardless of whether the police carried BWCs, although the majority of respondents believed that BWCs would improve police behaviour. Furthermore, an overwhelming majority of citizens were unaware that police officers already wore BWCs. Nevertheless, the authors noted a positive correlation between awareness of police use of BWCs and a positive perception of procedural justice and police behaviour (White et al., 2017). Furthermore, they claimed that their findings supported prompt adoption and implementation of BWCs in policing: 
The results presented here reinforce the widespread support for BWCs across numerous sectors and strongly suggest that this support extends to citizens who are most affected by the technology. This theme bodes well for the continued, rapid dissemination of BWCs in law enforcement. (White et al., 2017, p. 699).

Kerrison and colleagues (2018) reported a low degree of citizens' trust in the police and a positive attitude towards the use of BWCs, even though they also complained that police officers with BWCs no longer intervened in situations or made arrests in some neighbourhoods.

To view 'the public' as a homogenous group regarding attitudes towards police use of BWCs is problematic. As shown by Crow et al. (2017), non-white people, young people and people who self-reported a fear of crime were not as positive about the assumed benefits of BWCs as white people, older people and people not fearful of crime. Ariel (2016b) investigated if citizens report of crime changed when the police officers wore BWCs, and found that the reports increased in middle- and upper-class residential areas, but not in hot spots.

In summary, scholars and decision-makers should be careful not to place excessive weight on citizen attitudes as measurements of police legitimacy when determining whether BWCs should be used or not (see also Bromberg et al., 2018). Furthermore, researchers need to take into account that attitudes among citizens differ. Stating the fact that results show that citizens generally hold positive attitudes conceals that minority groups tend to hold more reluctant attitudes towards police use of BWCs. More research is needed on minority groups' attitudes towards police use of BWCs since - ultimately - it is the crisis in police legitimacy in relation to precisely these groups that is assumed to be amended by police use of BWCs. Furthermore, research on managerial - rather that citizens' - evaluations of BWC recordings is needed since it is, 
after all, supervisors who are responsible for evaluating and reprimanding officers. The focus in existing research of citizen evaluation indicates that BWCs are foremost understood as tools to improve police legitimacy vis-à-vis the public rather than measuring actual effects of BWCs in organizations' ability to hold officers accountable for misconduct.

The problem representation in published research on BWCs as a technology that will aid in restoring police legitimacy and decrease citizen dissatisfaction with the police places a great deal of trust in technological affordances. It is unlikely that a technological device like the BWC will be able to solve the lack of police legitimacy since technologies are ultimately social, i.e., their use and usefulness cannot be predetermined (Berg, 1998; De Laet \& Mol, 2000; Orlikowski, 1992; Oudshoorn \& Pinch, 2003). To view BWC technology as a solution to such a complex problem as police lack of legitimacy in the eyes of the public is not just a naïve technology determinism. It also rests on the assumption that technology and technology implementation is a purely 'rational' top-down process, thus completely disregarding the implementation process in itself, organizational hierarchies and work routines, and the people that will be using the technology (cf. Duffee, 2015). More research on implementation processes (see Sousa et al., 2016; White, Todak, et al., 2018 for an exception), as well as the dual modification of police work and technology that takes place in interaction between employees and technology when BWC use is implemented, is needed.

\subsection{Problem Representation: Police Officer Resistance Towards Use of BWCs}

Although only a few studies have examined the implementation processes and discuss aspects that influence the effects of BWCs other than the technology itself (see Drover \& Ariel, 2015; Sousa et al., 2016; White, Todak, et al., 2018 for exceptions), several 
studies present police officers' resistance towards BWCs as a problem that may slow down or hinder proper implementation and use of the technology. Consider this example:

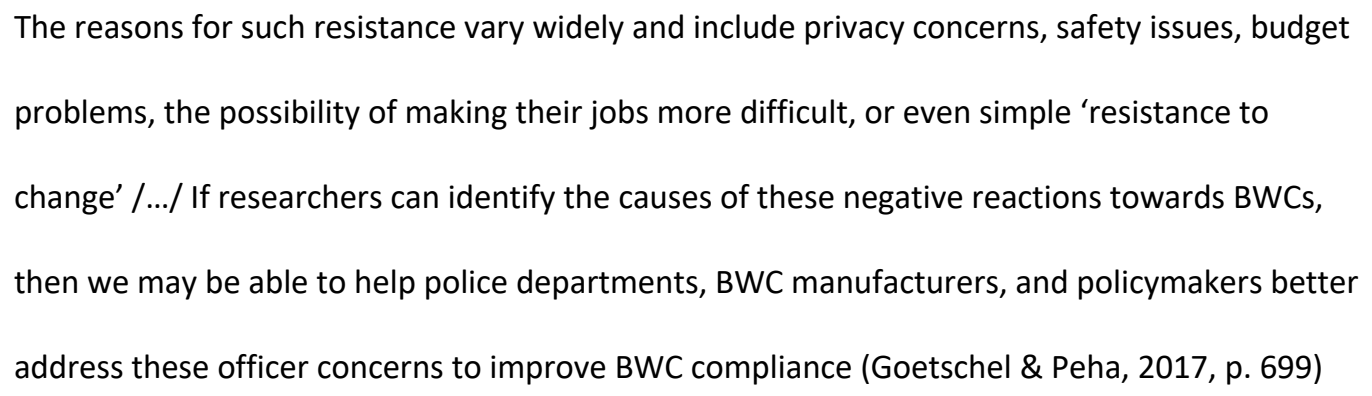

The majority of the research focuses on the attitudes and resistance among police officers on operational duties, i.e., those wearing BWCs. The research on management views is very limited (Lawshe et al., 2019; Pelfrey \& Keener, 2016, 2018; Smykla et al., 2016), as is an organizational perspective on BWCs (see Fan, 2018; Hendrix et al., 2019; Kyle \& White, 2017; Nowacki \& Willits, 2018 for exceptions). Likewise, only one study seems to have targeted 'specialty units' within the police (Gaub et al., 2020). Research on police attitudes assumes that officers on operational duties are either sceptical of BWCs or concerned, apprehensive and sometimes resistant to their adoption through their unions (e.g. Huff et al., 2018; White, Todak, et al., 2018; Wooditch et al., 2020), but they are assumed to be more positive once they start using BWCs (e.g. Young \& Ready, 2015). Hence, many studies have investigated police attitudes towards BWCs before and after implementation. Although some studies have shown that police officers had positive expectations of BWCs prior to implementation (Gaub et al., 2016; Gramagila \& Phillips, 2018; Jennings et al., 2014; Owens \& Finn, 2018; Pelfrey \& Keener, 2018; White, Todak, et al., 2018), most studies have reported that police officers who have used BWCs are more positive than they were before BWC implementation (Goetschel \& Peha, 2017; Cayli et al., 2018; Heumann et al., 2018; White, Todak, et al., 2018; Clare et al., 2019; Saulnier, Ermus St Louis, et al., 2019; 
Snyder et al., 2019; Wood \& Groff, 2019; Wooditch et al., 2020; see Headley et al., 2017 for an exception).

However, studies have also reported that after implementation, police officers had less faith in the camera's civilizing effects or that it increases officer safety, reported a negative impact on relations between police and citizens, and believed it had a less positive impact on quality of evidence than expected (Clare et al., 2019; Gaub et al., 2016; Morrow et al., 2016; White et al., 2019; Wooditch et al., 2020; see also White, Todak, et al., 2018 who found no evidentiary value). Snyder et al. (2019) showed that police officers' concerns about BWC recordings being used to monitor and discipline officers remained after implementation, and Schuck and Rabe-Hemp (2018) showed that implementation of BWCs resulted in a higher turnover rate among officers. Police officers have also been reported to interpret BWC implementation as a sign of distrust and believe it will further undermine the trust between officers and their superiors, on which the patrol officers depend (e.g. Adams \& Mastracci, 2019a, 2019b; Goetschel \& Peha, 2017; Lawshe et al., 2019; Makin, 2016; Pickering, 2020).

What is missing in studies on police officers' attitudes and resistance to BWCs is a genuine interest in understanding why officers resist BWC implementation or are hesitant towards using it. The representation of police officer resistance to BWC use as a problem rests on the assumptions that police officers (generally) misbehave and use more violence than necessary, and that those who have nothing to hide generally do not oppose being under surveillance. However, as Adams and Mastracci (2019a, p. 6) comment, the existing research on BWCs has been overly interested in police officers' misbehaviour by use of force 'despite evidence that use of force represents less than $1 \%$ of police-public interactions' (see also White, Gaub, et al., 2018). 
The assumption that those who have nothing to hide have nothing to fear is a well-known assumption in relation to many different surveillance technologies in contemporary societies (cf. Lyon, 2001). However, the assumption that officers who have nothing to hide will not resist BWCs is both oversimplified and risks (re)producing mistrust (Regan, 1995), by implying that resistance to BWC use indicates that one does have something to hide and neglecting other potential reasons for resistance and hesitation. Qualitative and explorative research is needed from the bottom-up to gain insight into officers' everyday work life and their work environment and provide deeper understandings of officers' attitudes and feelings of mistrust versus support from management and management views.

\section{Dominant Policing Problem Representations in BWC Research and Potential Consequences: A Concluding Discussion}

In this article, we have analysed policing problem representations guiding the available BWC research and assumed to be amended or improved with BWC use. In this concluding discussion, we summarize the existing problem representations characterizing the available research, and the presuppositions underlying the studies. Furthermore, we discuss what remains unproblematized in the dominant problem definitions and the potential consequences of how BWCs are portrayed. We also provide recommendations for future research on BWCs.

We have found that the existing research largely investigates the effectiveness of BWCs worn by police officers in the U.S., and build upon a set of dominant policing problem representations drawn on to warrant both BWC research and implementation: the police crisis in the U.S. and the police use of force, lack of oversight and control of police officers, citizen dissatisfaction and lack of police legitimacy, and police officer 
resistance towards BWC use. Assumptions underlying all four problem representations is that BWC technology will amend these problems and is legitimate and useful if the public supports it. Taken together, this enhances the representation of BWC technology as a self-evident means of improving community relations and police legitimacy.

However, arguably these problems cannot reasonably be expected to be solved by either BWC use or research on BWC use and utility. To explicitly or implicitly assume that BWC technology provides a solution to such a complex set of problems assumes that technology implementation is a purely 'rational' top-down process, and disregards existing power structures and relations (cf. Duffee, 2015) and perhaps the scope of the police legitimacy crisis in the U.S.

It is not surprising that research has been unable to find support for the expected effects of BWCs (with the exception of a decrease in the number of citizen complaints). This has, however, not curbed some researchers' enthusiasm for BWC use, who refer to lack of effects as 'implementation failures' and recommend police agencies to enforce implementation and activation of BWCs (Ariel et al., 2016a; Drover \& Ariel, 2015; Hedberg et al., 2017; Lawrence et al., 2019; Malm, 2019, p. 121f.; Sousa et al., 2018). In this context, there is a risk that officer apprehensions or resistance to BWC use per se may be taken to indicate misconduct. By reinforcing the assumption of police misbehaviour, research articles risk creating a demand for more monitoring and control of police officers, which in turn risks undermining trust and organizational justice within police agencies and being contra effective in solving the policing problems as represented in research.

A potential consequence of the assumption of police officers' (general) misbehaviour and BWC technology as a solution to the policing crisis through deterrence and civilizing effects is an oversimplified understanding of police work, 
interactions between police officers and citizens, and organizational conditions in police agencies. Another consequence may be a polarized understanding, where police officers are evaluated as either good or bad and where more intense monitoring of police officers will rightly punish the "bad" ones and support "good" ones.

Arguably, published research in which scholars warrant their studies, present results, generalize findings and provide policy and practice recommendations are 'prescriptive texts' (Bacchi 2012). They thereby take part in modifying policing problems and BWCs as a solution (cf. Asdal 2015). While the mainstream BWC research contribute to fortifying the policing problem representations discussed above, quite another type of BWC research also does modifying work, by questioning the utility of BWCs as a solution to the police crisis - although this type of research is rare. This latter type of research argues that BWCs will change neither policing practices nor their fundamental values and instead risk resulting in 'a recursive cycle of technological control and officer resistance' (Koslicki, 2019; Ray et al., 2017; Stalcup \& Hahn, 2016, p. 495). In this article, we align with this latter type of modifying work in the sense that we, too, suggest that altogether different ways of attending to the policing problems discussed in mainstream BWC research is needed.

We therefore, firstly, call for future research about policing and policing problems that engages with issues such as structural racism and police violence (Moore et al., 2018; e.g. Schrader, 2017) as well as organizational-level factors (e.g. Klinger, 2020; Sherman, 2020). BWC implementation and use cannot be studied in isolation as a solution to the problem of police shootings, regardless of what stakeholders and the public demand. Secondly, we call for BWC research that acknowledges and departs from policing problems as they are represented in contexts in other countries, e.g. issues concerning the safety of and the wider work environment of officers (Coudert et al., 
2015; prop. 2017/18:99). Thirdly, we call for more research that does not adopt the many positive expectations regarding BWCs with the objective to evaluate whether the expectations hold true, but instead takes everyday police practices and challenges as the point of departure. Lastly, we call for research about BWC use in other social control occupations than the police. BWC use is spreading into adjacent social control professions, and translating results from studies on police officers to other occupations is problematic because the police have been delegated special authority to use force against and inflict harm on citizens to solve (policing) problems.

\section{References}

*Adams, I. and Mastracci, S., 2019a. Police Body-Worn Cameras: Effects on Officers' Burnout and Perceived Organizational Support. Police Quarterly, 22 (1), 5-30.

*Adams, I. and Mastracci, S., 2019b. Police Body-Worn Cameras: Development of the Perceived Intensity of Monitoring Scale. Criminal Justice Review, 44 (3), 386-405.

*Ariel, B., 2016a. Police Body Cameras in Large Police Departments. Journal of Criminal Law \& Criminology, 106 (4), 729-768.

*Ariel, B., 2016b. Increasing cooperation with the police using Body Worn Cameras. Police Quarterly, 19 (3), 326-362.

*Ariel, B., Farrar, W.A., and Sutherland, A., 2015. The Effect of Police Body-Worn Cameras on Use of Force and Citizens' Complaints Against the Police: A Randomized Controlled Trial. Journal of Quantitative Criminology, 31 (3), 509-535.

*Ariel, B., Newton, M., McEwan, L., Ashbridge G. A., Weinborn C., \& B. Hagit Sabo. (2019). Reducing Assaults Against Staff Using Body-Worn Cameras (BWCs) in Railway Stations. Criminal Justice Review, 44(1), 76-93.

*Ariel, B., Sutherland, A., Henstock, D., Young, J., Drover, P., Sykes, J., Megicks, S., 
and Henderson, R., 2016a. Report: increases in police use of force in the presence of body-worn cameras are driven by officer discretion: a protocol-based subgroup analysis of ten randomized experiments. Journal of Experimental Criminology, 12 (3), 453-463. *Ariel, B., Sutherland, A., Henstock, D., Young, J., Drover, P., Sykes, J., Megicks, S., and Henderson, R., 2016b. Wearing body cameras increases assaults against officers and does not reduce police use of force: Results from a global multi-site experiment. European Journal of Criminology, 13 (6), 744-755.

*Ariel, B., Sutherland, A., Henstock, D., Young, J., Drover, P., Sykes, J., Megicks, S., and Henderson, R., 2017. "Contagious accountability”: A global multisite randomized controlled trial on the effect of police body-worn cameras on citizens' complaints against the police. Criminal Justice and Behavior, 44 (2), 293-316.

*Ariel, B., Sutherland, A., Henstock, D., Young, J., Drover, P., Sykes, J., Megicks, S., and Henderson, R., 2018. Paradoxical effects of self-awareness of being observed: Testing the effect of police body-worn cameras on assaults and aggression against officers. Journal of Experimental Criminology, 14 (1), 19-47.

Arksey, H., \& O’Malley, L. (2005). Scoping studies: Towards a methodological framework. International Journal of Social Research Methodology, 8(1), 19-32.

Asdal, K. (2015). What is the issue? The transformative capacity of documents.

Distinktion: Scandinavian Journal of Social Theory, 16(1), 74-90.

Bacchi, C. (2009). Analysing policy: What's the problem represented to be? Frenchs Forest: Pearson Education.

Bacchi, C. (2012). Why Study Problematizations? Making Politics Visible. Open Journal of Political Science, 2(1), 1-8.

Becker, H. S. (1963). Outsiders: Studies in the sociology of deviance. New York: Free Press

Becker, H. S. (2007). Telling about society. Chicago: University of Chicago Press 
Berg, M. (1998). The Politics of Technology: On Bringing Social Theory into Technological Design. Science, Technology, \& Human Values, 23(4), 456-490. Boels, D., \& Verhage, A. (2016). Plural policing: A State-of-the-Art Review. Policing: An International Journal of Police Strategies \& Management, 39(1), 2-18.

*Boivin, R., Gendron, A., Faubert, C., and Poulin, B., 2017. The body-worn camera perspective bias. Journal of Experimental Criminology, 13 (1), 125-142.

*Braga, A.A., Barao, L.M., Zimmerman, G.M., Douglas, S., and Sheppard, K., 2019. Measuring the direct and spillover effects of body worn cameras on the civility of police-citizen encounters and police work activities. Journal of Quantitative Criminology.

*Braga, A.A., Sousa, W.H., Coldren, J.R., Jr, and Rodriguez, D., 2018. The Effects of Body-Worn Cameras om Police Activity and Police-Citizen Encounters: A Randomized Colntrolled Trial*. Journal of Criminal Law \& Criminology, 108 (3), 511-538.

*Bromberg, D.E., Charbonneau, É., and Smith, A., 2018. Body-Worn Cameras and Policing: A List Experiment of Citizen Overt and True Support. Public Administration Review, 78 (6), 883-891.

*Cayli, B., Hargreaves, C., and Hodgson, P., 2018. Body-worn cameras: determining the democratic habitus of policing. Safer Communities, 17 (4), 213-223.

Christie, N. (2001). Crime control as industry: Towards gulags, Western style. New York: Routledge.

*Clare, J., Henstock Darren, McComb, C., Newland, R., Barnes, G.C., Lee, M., and Taylor, E., 2019. Police, Public, and Arrestee Perceptions of Body-Worn Video: A Single Jurisdictional Multiple-Perspective Analysis. Criminal Justice Review, 44 (3), $304-321$.

Coudert, F., Butin, D., \& Le Métayer, D. (2015). Body-worn cameras for police 
accountability: Opportunities and risks. Computer Law \& Security Review, 31(6), 749762.

*Crow, M.S., Snyder, J.A., Crichlow, V.J., and Smykla, J.O., 2017. Community perceptions of police body-worn cameras: The impact of views on fairness, fear, performance, and privacy. Criminal Justice and Behavior, 44 (4), 589-610.

*Culhane, S.E., Boman, J.H., IV, and Schweitzer, K., 2016. Public perceptions of the justifiability of police shootings: The role of body cameras in a pre- and post-Ferguson experiment. Police Quarterly, 19 (3), 251-274.

*Culhane, S.E. and Schweitzer, K., 2018. Police shootings and body cameras one year post-Ferguson. Policing \& Society, 28 (9), 1038-1049.

De Laet, M., \& Mol, A. (2000). The Zimbabwe bush pump: Mechanics of a fluid technology. Social Studies of Science, 30(2), 225-263.

*Demir, M., 2019. Citizens' perceptions of body-worn cameras (BWCs): Findings from a quasi-randomized controlled trial. Journal of Criminal Justice, 60, 130-139.

*Demir, M., Apel, R., Braga, A.A., Brunson, R.K., and B. Ariel, 2020. Body Worn Cameras, Procedural Justice, and Police Legitimacy: A Controlled Experimental Evaluation of Traffic Stops. Justice Quarterly : JQ, 37 (1), 53-84.

*Drover, P. and Ariel, B., 2015. Leading an experiment in police body-worn video cameras. International criminal justice review, 25 (1), 80-97.

Duffee, D. E. (2015). Why is criminal justice theory important? In E. R. Maguire \& D. E. Duffee (Eds.), Criminal justice theory: Explaining the nature and behavior of criminal justice (pp. 5-26). Routledge.

*Fallik, S.W., Deuchar, R., and Crichlow, V.J., 2018. Body-worn cameras in the postferguson era: An exploration of law enforcement perspectives. Journal of Police and Criminal Psychology. 
*Fan, M.D., 2018. Body Cameras, Big Data, and Police Accountability. Law \& Social Inquiry, 43 (4), 1236-1256.

Garland, D. (2001). The culture of control. Chicago: The University of Chicago Press

*Gaub, J.E., Choate, D.E., Todak, N., Katz, C.M., and White, M.D., 2016. Officer perceptions of body-worn cameras before and after deployment: A study of three departments. Police Quarterly, 19 (3), 275-302.

*Gaub, J.E., Todak Natalie, and White, M.D., 2020. One Size Doesn’t Fit All. International Criminal Justice Review, 30 (2), 136-155.

Gaub, J. E., \& White, M. D. (2020). Open to interpretation: Confronting the challenges of understanding the current state of body-worn camera research. American Journal of Criminal Justice. https://doi.org/10.1007/s12103-020-09518-4

*Goetschel, M. and Peha, J.M., 2017. Police perceptions of body-worn cameras. American Journal of Criminal Justice, 42 (4), 698-726.

Gough, D., Oliver, S., \& Thomas, J. (2017). An introduction to systematic reviews. Los Angeles: Sage.

*Graham, A., McManus, H.D., Cullen, F.T., Burton, V.S., Jr, and Jonson, C.L., 2019. Videos Don't Lie: African Americans' Support for Body-Worn Cameras. Criminal Justice Review, 44 (3), 284-303.

*Gramagila, J.A. and Phillips, S.W., 2018. Police Officers' Perceptions of Body-Worn Cameras in Buffalo and Rochester. American Journal of Criminal Justice : AJCJ, 43 (2), 313-328.

*Groff, E.R., Haberman, C., and Wood, J.D., 2019. The effects of body-worn cameras on police-citizen encounters and police activity: Evaluation of a pilot implementation in philadelphia, pa. Journal of Experimental Criminology.

*Guzik, K., Sesay, A., Oh, O., Ramirez, R., and Tong, T., 2019. Making the material 
routine: a sociomaterial study of the relationship between police body worn cameras (BWCs) and organisational routines. Policing and Society, 1-16.

*Hamm, J.A., A M D’Annunzio, Bornstein, B.H., Hoetger, L., and Herian, M.N., 2019.

Do body-worn cameras reduce eyewitness cooperation with the police? An experimental inquiry. Journal of Experimental Criminology, 1-17.

*Headley, A.M., Guerette, R.T., and Shariati, A., 2017. A field experiment of the impact of body-worn cameras (BWCs) on police officer behavior and perceptions. Journal of Criminal Justice, 53, 102-109.

*Hedberg, E.C., Katz, C.M., and Choate, D.E., 2017. Body-Worn Cameras and Citizen Interactions with Police Officers: Estimating Plausible Effects Given Varying Compliance Levels. Justice Quarterly: JQ, 34 (4), 627-651.

*Hendrix, J.A., Taniguchi, T., Strom, K.J., Aagaard, B., and Johnson, N., 2019. Strategic policing philosophy and the acquisition of technology: findings from a nationally representative survey of law enforcement. Policing \& Society, 29 (6), 727743.

*Henstock, D. and Ariel, B., 2017. Testing the effects of police body-worn cameras on use of force during arrests: A randomised controlled trial in a large British police force. European Journal of Criminology, 14 (6), 720-750.

*Heumann, M., Kavin, R., Chugh, A., and Cassak, L., 2018. In the Eyes of the Law: The Effects of Body-Worn Cameras on Police Behavior, Citizen Interactions, and Privacy. Criminal Law Bulletin, 54 (3), 584-627.

*Huff, J., Katz, C.M., and Webb, V.J., 2018. Understanding police officer resistance to body-worn cameras. Policing, 41 (4), 482-495.

*Jennings, W.G., Fridell, L.A., and Lynch, M.D., 2014. Cops and cameras: Officer perceptions of the use of body-worn cameras in law enforcement. Journal of Criminal 
Justice, 42 (6), 549-556.

*Jennings, W.G., Fridell, L.A., Lynch, M., Jetelina, K.K., and Reingle Gonzalez, J.M., 2017. A quasi-experimental evaluation of the effects of police body-worn cameras (BWCs) on response-to-resistance in a large metropolitan police department. Deviant Behavior, 38 (11), 1332-1339.

*Jennings, W.G., Lynch, M.D., and Fridell, L.A., 2015. Evaluating the impact of police officer body-worn cameras (BWCs) on response-to-resistance and serious external complaints: Evidence from the Orlando police department (OPD) experience utilizing a randomized controlled experiment. Journal of Criminal Justice, 43 (6), 480-486.

*Jiang, F., Xie, C., and Ellis, T., 2020. Police Officers' Perceptions of Body-Worn Video Cameras in Beijing. International Criminal Justice Review, doi:1057567720919913.

*Jones, K.A., Crozier, W.E., and Strange, D., 2017. Believing is seeing: Biased viewing of body-worn camera footage. Journal of Applied Research in Memory and Cognition, $6(4), 460-474$.

*Jones, K.A., Crozier, W.E., and Strange, D., 2018. Objectivity is a myth for you but not for me or police: A bias blind spot for viewing and remembering criminal events. Psychology, Public Policy, and Law, 24 (2), 259-270.

*Jones, K.A., Crozier, W.E., and Strange, D., 2020. Look there! The effect of perspective, attention, and instructions on how people understand recorded police encounters. Behavioral Sciences \& the Law, 37(6): 711-731.

Jones, T., \& Newburn, T. (2006). Understandig plural policing. In T. Jones \& T. Newburn (Eds.), Plural Policing: A Comparative Perspective (pp. 1-11). Abingdon : Routledge. 
*Kerrison, E.M., Cobbina, J., and Bender, K., 2018. Stop-gaps, lip service, and the perceived futility of body-worn police officer cameras in Baltimore City. Journal of Ethnic \& Cultural Diversity in Social Work, 27 (3), 271-288.

Klinger, D. (2020). Organizational Accidents and Deadly Police-Involved Violence: Some Thoughts on Extending Theory, Expanding Research, and Improving Police Practice. The ANNALS of the American Academy of Political and Social Science, $687(1), 28-48$.

*Koen, M.C., Willis, J.J., and Mastrofski, S.D., 2019. The effects of body-worn cameras on police organisation and practice: a theory-based analysis. Policing and Society, 29 (8), 968-984.

*Koslicki, W.M., 2019. Accountability or Efficiency? Body-Worn Cameras as Replicative Technology. Criminal Justice Review, 44 (3), 356-368.

Kraska, P. B. (2006). Criminal Justice Theory: Toward Legitimacy and an Infrastructure. Justice Quarterly, 23(2), 167-185.

*Kyle, M.J. and White, D.R., 2017. The impact of law enforcement officer perceptions of organizational justice on their attitudes regarding body-worn cameras. Journal of crime and justice, 40 (1), 68-83.

*Lawrence, D.S., McClure, D., Malm Aili, Lynch, M., and La Vigne Nancy, 2019. Activation of Body-Worn Cameras: Variation by Officer, Over Time, and by Policing Activity. Criminal Justice Review, 44 (3), 339-355.

*Lawrence, D.S. and Peterson, B.E., 2019. How do body-worn cameras affect the amount and makeup of police-initiated activities? A randomized controlled trial in milwaukee, wisconsin. Journal of Experimental Criminology. 16 (4): 481-503 *Lawshe, N.L., Burruss, G.W., Giblin, M.J., and Schafer, J.A., 2019. Behind the lens: police attitudes toward body-worn cameras and organizational justice. Journal of Crime 
and Justice, 42 (1), 78-97.

*Lee, M., Taylor, E., and Willis, M., 2019. Being held to account: Detainees’ perceptions of police body-worn cameras. Australian \& New Zealand Journal of Criminology, 52 (2), 174-192.

Levac, D., Colquhoun, H., \& O’Brien, K. K. (2010). Scoping studies: Advancing the methodology. Implementation Science, 5(1), 69.

Loseke, D. R. (2003). Thinking about social problems: An introduction to constructionist perspectives. New York: Aldine de Gruyter.

Lum, C., Koper, C. S., Wilson, D. B., Stoltz, M., Goodier, M., Eggins, E., Higginson, A., \& Mazerolle, L. (2020). Body-worn cameras' effects on police officers and citizen behavior: A systematic review. Campbell Systematic Reviews, 16(3), Article number: e1112.

Lum, C., Stoltz, M., Koper, C. S., \& Scherer, J. A. (2019). Research on body-worn cameras. Criminology \& Public Policy, 18(1), 93-118.

Lyon, D. (2001). Surveillance society: Monitoring everyday life. Buckingham: Open Univ. Press.

*Makin, D.A., 2016. When the watchers are watched: An interpretive phenomenological analysis of body-worn cameras. Journal of qualitative criminal justice \& criminology, 4 (1), 113-151.

Malm, A. (2019). Promise of police body-worn cameras. Criminology \& Public Policy, 18(1), 119-130.

*McCamman, M. and Culhane, S., 2017. Police body cameras and us: Public perceptions of the justification of the police use of force in the body camera era. Translational Issues in Psychological Science, 3 (2), 167-175.

*McCluskey, J.D., Uchida, C.D., Solomon, S.E., Alese Wooditch, Connor, C., and 
Revier, L., 2019. Assessing the effects of body-worn cameras on procedural justice in the Los Angeles Police Department. Criminology, 57 (2), 208-236.

*Miethe, T.D., Lieberman, J.D., Heen Miliaikeala S J, and Sousa, W.H., 2019. Public Attitudes About Body-Worn Cameras in Police Work: A National Study of the Sources of Their Contextual Variability. Criminal Justice Review, 44 (3), 263-283.

*Mitchell, R.J., Barak, A., Firpo, M.E., Fraiman, R., Castillo, F. del, Hyatt, J.M., Weinborn C., and B. Sabo Hagit, 2018. Measuring the effect of body-worn cameras on complaints in Latin America. Policing, 41 (4), 510-524.

Moore, S. E., Robinson, M. A., Clayton, D. M., Adedoyin, A. C., Boamah, D. A., Kyere, E., \& Harmon, D. K. (2018). A Critical Race Perspective of Police Shooting of Unarmed Black Males in the United States: Implications for Social Work. Urban Social Work, 2(1), 33-47.

*Morrow, W.J., Katz, C.M., and Choate, D.E., 2016. Assessing the impact of police body-worn cameras on arresting, prosecuting, and convicting suspects of intimate partner violence. Police Quarterly, 19 (3), 303-325.

Munn, Z., Peters, M. D. J., Stern, C., Tufanaru, C., McArthur, A., \& Aromataris, E. (2018). Systematic review or scoping review? Guidance for authors when choosing between a systematic or scoping review approach. BMC Medical Research Methodology, 18(1), 143.

*Naoroz, C. and Cleary, H., 2019. News Media Framing of Police Body-Worn Cameras: A Content Analysis. Policing: A Journal of Policy and Practice.

*Nowacki, J.S. and Willits, D., 2018. Adoption of body cameras by United States police agencies: an organisational analysis. Policing \& Society, 28 (7), 841-853.

Orlikowski, W. J. (1992). The Duality of Technology: Rethinking the Concept of Technology in Organizations. Organization Science, 3(3), 398-427. 
Oudshoorn, N. E., \& Pinch, T. (2003). How users matter: The co-construction of users and technologies. Cambridge, Mass.: MIT press.

*Owens, C. and Finn, W., 2018. Body-worn video through the lens of a cluster randomized controlled trial in London: Implications for future research. Policing: $A$ Journal of Policy and Practice, 12 (1), 77-82.

*Pelfrey, W.V. and Keener, S., 2016. Police body worn cameras: a mixed method approach assessing perceptions of efficacy. Policing, 39 (3), 491-506.

*Pelfrey, W.V. and Keener, S., 2018. Body-worn cameras and officer perceptions: a mixed-method pretest posttest of patrol officers and supervisors. Journal of Crime and Justice, 41 (5), 535-552.

*Pickering, J.C., 2020. Officers' perceptions regarding the unexpected effects of bodyworn cameras. Policing, 43 (2), 390-402.

Power, M. (2000). The Audit Society-Second Thoughts. International Journal of Auditing, 4(1), 111-119.

*Ramirez, F.A., 2018. Social media affordances in the context of police transparency: An analysis of the first public archive of police body camera videos. Journal of Applied Communication Research, 46 (5), 621-640.

*Ray, R., Marsh, K., and Powelson, C., 2017. Can cameras stop the killings? Racial differences in perceptions of the effectiveness of body-worn cameras in police encounters. Sociological Forum, 32 (Suppl 1), 1032-1050.

*Ready, J.T. and Young, J.T.N., 2015. The impact of on-officer video cameras on police-citizen contacts: findings from a controlled experiment in Mesa, AZ. Journal of Experimental Criminology, 11 (3), 445-458.

Regan, P. M. (1995). Legislating Privacy: Technology, Social Values, and Public Policy. Chapel Hill, NC: University of North Carolina Press. 
*Rowe, M., Pearson, G., and Turner, E., 2018. Body-worn cameras and the law of unintended consequences: Some questions arising from emergent practices. Policing: $a$ journal of policy and practice, 12 (1), 83-90.

*Saulnier, A., Burke, K.C., and Bottoms, B.L., 2019. The effects of body-worn camera footage and eyewitness race on jurors' perceptions of police use of force. Behavioral Sciences \& the Law, 37 (6), 732-750.

*Saulnier, A., Ermus, S., and McCarty, W., 2019. Procedural justice concerns and support for BWCs: turning the lens to officer perceptions. Policing, 42 (4), 671-687. *Schneider, C.J., 2018. Body Worn Cameras and police image work: News media coverage of the Rialto Police Department's body worn camera experiment. Crime, Media, Culture, 14 (3), 449-466.

Schrader, S. (2017). More than cosmetic changes: The challenges of experiments with police demilitarization in the 1960s and 1970s. Journal of Urban History, 46(5), 10021025.

*Schuck, A.M. and Rabe-Hemp, C.E., 2018. Investing in people: salary and turnover in policing. Policing, 41 (1), 113-128.

Sherman, L. W. (2020). Evidence-Based Policing and Fatal Police Shootings: Promise, Problems, and Prospects. The ANNALS of the American Academy of Political and Social Science, 687(1), 8-26.

Simmons, K. C. (2014). Body-Mounted Police Cameras: A Primer on Police Accountability vs. Privacy. Howard Law Journal, 58(3), 881-890.

Simon, J., \& Feeley, M. M. (1994). Actuarial justice: The emerging new criminal law. In D. Nelken (Ed.), The futures of criminology. London: Sage.

*Smykla, J.O., Crow, M.S., Crichlow, V.J., and Snyder, J.A., 2016. Police Body-Worn Cameras: Perceptions of Law Enforcement Leadership. American Journal of Criminal 
Justice : AJCJ, 41 (3), 424-443.

*Snyder, J.A., Crow, M.S., and Smykla J. O., 2019. Police Officer and Supervisor Perceptions of Body-Worn Cameras Pre- and Postimplementation: The Importance of Officer Buy-in. Criminal Justice Review, 44 (3), 322-338.

*Sousa, W.H., Coldren, J.R., Jr., Rodriguez, D., and Braga, A.A., 2016. Research on body worn cameras: Meeting the challenges of police operations, program implementation, and randomized controlled trial designs. Police Quarterly, 19 (3), 363384.

*Sousa, W.H., Miethe, T.D., and Sakiyama, M., 2018. Inconsistencies in public opinion of body-worn cameras on police: Transparency, trust, and improved police-citizen relationships. Policing: A Journal of policy and Practice, 12 (1), 100-108.

*Stalcup, M. and Hahn, C., 2016. Cops, cameras, and the policing of ethics. Theoretical Criminology, 20 (4), 482-501.

*Sutherland, A., Ariel, B., Farrar, W., and Anda, R.D., 2017. Post-experimental followups-Fade-out versus persistence effects: The Rialto police body-worn camera experiment four years on. Journal of Criminal Justice, 53, 110-116.

*Todak, Natalie, Gaub, J.E., and White, M.D., 2018. The importance of external stakeholders for police body-worn camera diffusion. Policing, 41 (4), 448-464.

*Turner, B.L., Caruso, E.M., Dilich, M.A., and Roese, N.J., 2019. Body camera footage leads to lower judgments of intent than dash camera footage. PNAS Proceedings of the National Academy of Sciences of the United States of America, 116 (4), 1201-1206.

*Wallace, D., White, M.D., Gaub, J.E., and Todak, N., 2018. Body-Worn Cameras as a Potential Source of Depolicing: Testing for Camera-Induced Passitivity. Criminology, $56(3), 481-509$.

*White, M.D., Gaub, J.E., Malm, A., and Padilla, K.E., 2019. Implicate or Exonerate? 
The Impact of Police Body-Worn Cameras on the Adjudication of Drug and Alcohol Cases. Policing: A Journal of Policy and Practice. doi:10.1093/police/paz043

*White, M.D., Gaub, J.E., and Todak, N., 2018. Exploring the Potential for Body-Worn Cameras to Reduce Violence in Police-Citizen Encounters. Policing-a Journal of Policy and Practice, 12 (1), 66-76.

*White, M.D., Todak, N., and Gaub, J.E., 2017. Assessing citizen perceptions of bodyworn cameras after encounters with police. Policing, 40 (4), 689-703.

*White, M.D., Todak, N., and Gaub, J.E., 2018. Examining Body-Worn Camera Integration and Acceptance Among Police Officers, Citizens, and External Stakeholders. Criminology \& Public Policy, 17 (3), 649-677.

*Wood, J.D. and Groff, E.R., 2019. Reimagining Guardians and Guardianship With the Advent of Body Worn Cameras. Criminal Justice Review, 44 (1), 60-75.

*Wooditch, A., Uchida, C.D., Solomon, S.E., Revier, L., Connor, C., Shutinya, M., McCluskey, J., and Swatt, M.L., 2020. Perceptions of body-worn cameras: Findings from a panel survey of two lapd divisions. American Journal of Criminal Justice. *Young, J.T.N. and Ready, J.T., 2015. Diffusion of ideas and technology: The role of networks in influencing the endorsement and use of on-officer video cameras. Journal of Contemporary Criminal Justice, 31 (3), 243-261.

*Young, J.T.N. and Ready, J.T., 2018. A longitudinal analysis of the relationship between administrative policy, technological preferences, and body-worn camera activation among police officers. Policing: A Journal of Policy and Practice, 12 (1), $27-42$. 
Figure 1. Graphical representation of the article screening process.

Databases: Criminal Justice Database, IBSS, PsycInfo

Search words: body-worn camera*, body-worn video*, body cam*, BWC, BWV, BWVC, officer video*, on-officer video*, wearable camera*, wearable video*, wearable video device*

Manually searched journals: International Criminal Justice Review; Policing: A

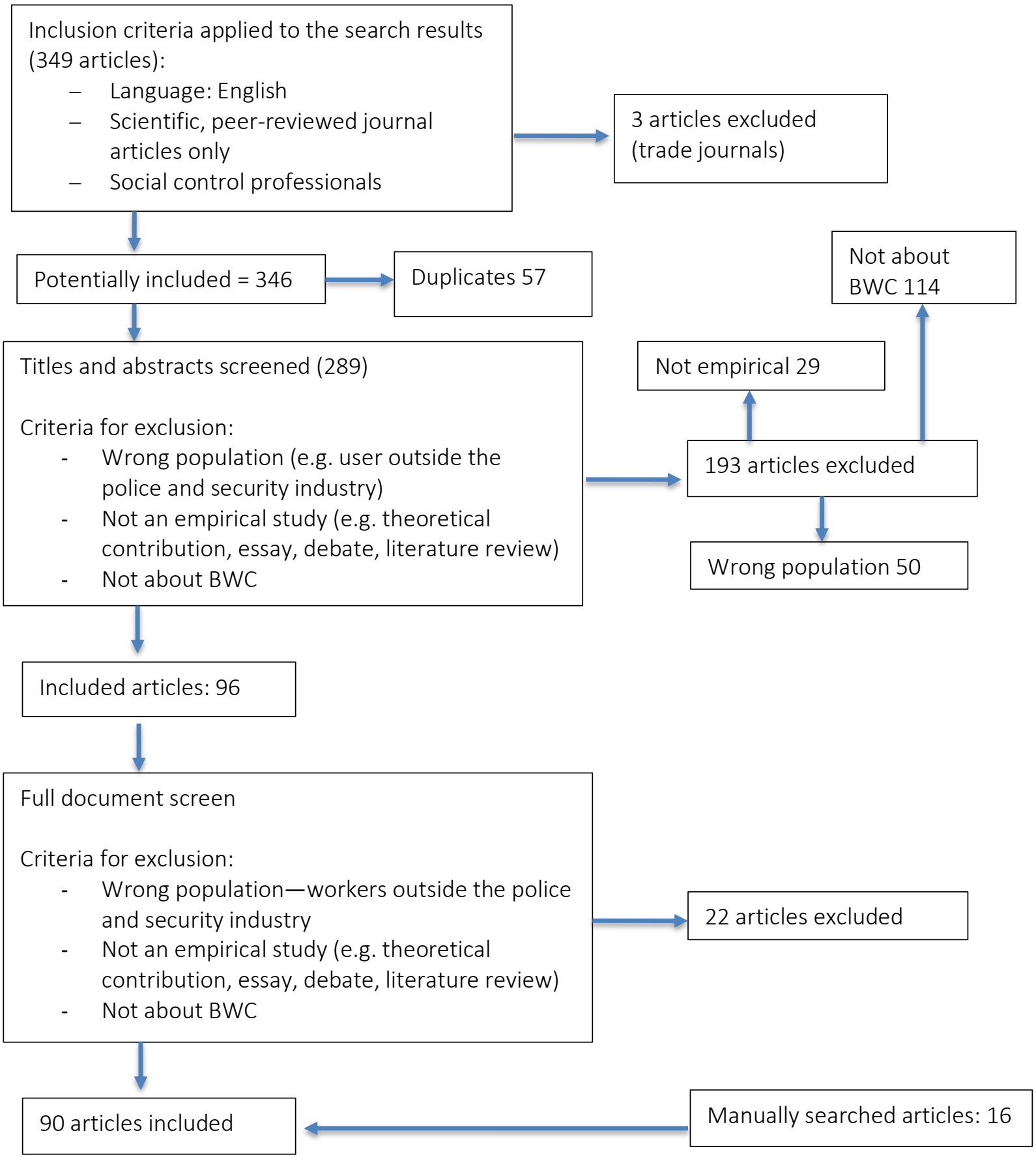




\section{Notes}

${ }^{\mathrm{i}}$ https://www.axis.com/en-gb/products/wearables 2020-01-14

ii Just a few studies have been conducted in the U.K. (6), with occasional projects in Australia (2), Turkey (2), China (1) and Uruguay (1). In two articles, it was not possible to determine in which country the research was conducted (Ariel et al., 2017, 2018). 